\title{
The research for the test model and the finite element model of the multi-ribbed composite wall
}

\author{
Kun Qian ${ }^{1, a}$, Guanghui Jia ${ }^{1, b}$ and Tian $\mathrm{Xia}^{2, \mathrm{c}}$ \\ ${ }^{1}$ Jilin Jianzhu University, Changchun 130118, China \\ ${ }^{2}$ Shandong Institute Of Architectural Design co. LTD. Of China Railway First Design Institute, Weihai, \\ 264200, China \\ a916249852@qq.com, bulcjgh001@163.com 410360361@qq.com
}

Keywords: Multi-ribbed composite wall; The Finite element calculation; Test model; Bearing capacity; Hysteresis curve.

Abstract: On the basis of experimental study, we used the finite element software ABAQUS to establish the nonlinear finite element numerical model of multi-ribbed composite wall, simulating model for reference [7], analyzed the stress of multi-ribbed composite wall structure, and the test results and the finite element model results were analyzed. Then, the wall in the case of filling blocks, we analyzed the consistent degree of the finite element calculation results and the test results. Finally, we stimulated the filled block walls under horizontal low cycle loading, and analyzed the hysteretic curve of the finite element model and the test model.

\section{Introduction}

As the main force of multi-ribbed wall structure component, multi-ribbed composite wall has important influence on structure response characteristics. Therefore, the establishment of calculation model of multi-ribbed composite wall and its mechanical performance research have profound practical significance on further improving the theoretical system of the new structure .

\section{The basic parameters of test model and test method}

The test model geometry size and reinforcement information are shown in figure 1 and 2, and KW-1 is empty sash frame.KW-2 wall body size and reinforcement are same with KW-1, but KW-2 sash is filled with gas concrete block. The wall's thickness is $100 \mathrm{~mm}$, long $\mathrm{x}$ high $=1400 \mathrm{~mm} \times 440 \mathrm{~mm}$, and rib beam and column section size are: high $\mathrm{x}$ wide $=50 \mathrm{~mm} \times 100 \mathrm{~mm}$. The outside frame size of column section and beam section are: high $\mathrm{x}$ wide $=150 \mathrm{~mm} \times 100 \mathrm{~mm}$.

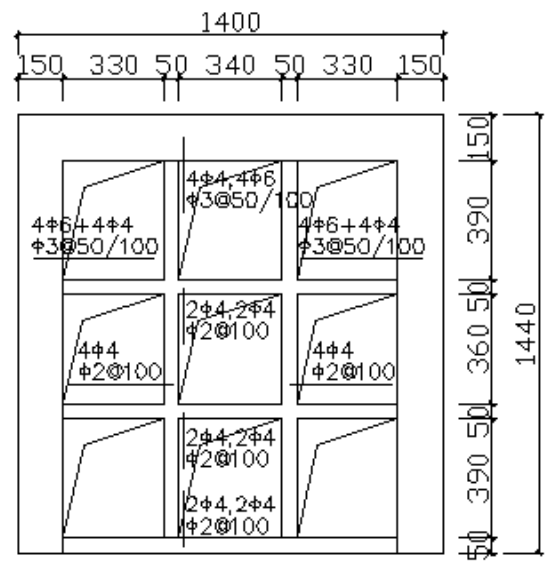

Fig. 1 Section size and steel bar details of KW-1

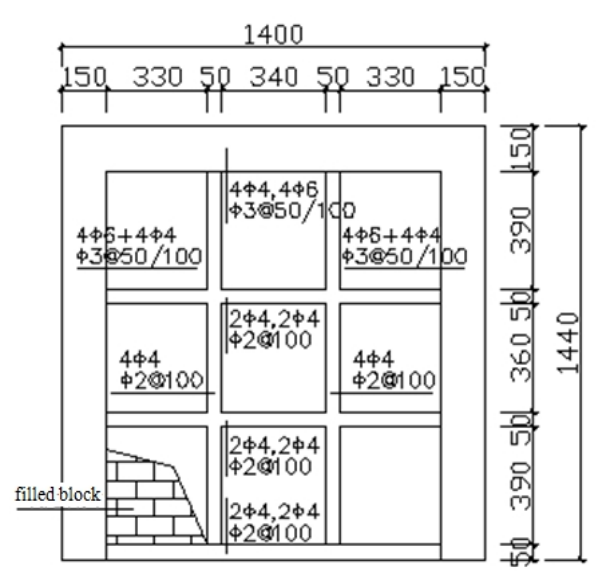

Fig. 2 Section size and steel bar details of KW-2

For KW-1 and $2 \mathrm{KW}-2$ monotonic loading pushover tests, first of all, imposing $110 \mathrm{KN}$ vertical load, axial compression ratio is 0.1 , then on top of the wall imposing monotonic horizontal load until the wall destroyed. For KW-2 low reversed cyclic loading test, firstly we impose $110 \mathrm{KN}$ vertical load, and then impose horizontal low cycle load. 


\section{ABAQUS model establishment process}

Firstly we set up the outside frame, rib, filling block, longitudinal reinforcement and stirrup etc., then enter the corresponding material properties, and then assemble each entity, KW-1 model after assembled as shown in figure $3 \mathrm{t}$

The outside framework, rib and lattice materials, reinforcement of KW-2 are the same with KW-1, but the sash of KW-2 is filled with gas concrete block, as shown in figure 4.

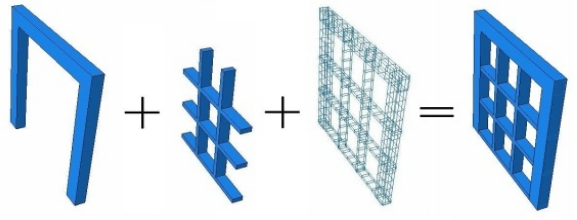

Fig. 3 assembly of KW-1

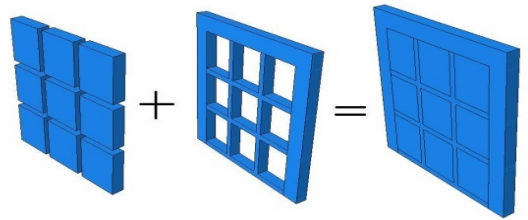

Fig.4 assembly of KW-2

Set up three analytic steps, boundary conditions, the vertical load and horizontal load respectively. Interaction included in the KW-1 is the bound between rib and outer frame, the steel bar embedded in concrete, and the KW-2 includes the interaction between the block and sash. Boundary condition is assumed that all nodes at the bottom of the wall are completely fixed.

Equivalent in the finite element model of plane uniformly distributed load is $785714 \mathrm{~N} / \mathrm{m}^{2}$ evenly on the top plane. When imposing the horizontal load, we set the reference point on the surface of the roof, and make it couple with the top of the model. When monotonic pushover test, we impose unilateral displacement on reference point, and amplitude is set in low cycle reciprocating load, increasing $5 \mathrm{~mm}$ per level displacement to conduct cycling displacement loading.

In order to guarantee the accuracy, improve the efficiency of computing, reference [4], this paper sets up the overall size of $50 \mathrm{~mm}$ to distribute grid seed, the grid automatically.

Finally, submit the job, and solve it.

\section{The finite element numerical simulation results}

In the reference [7], this article compares the calculated value of ABAQUS model with experiment data of KW-1. Each feature point test data as shown in table 1, the load-displacement curve of KW-1 experimental and finite element calculation values as shown in figure 5.

Table1 experimental data of KW-1

\begin{tabular}{c|c|c|c}
\hline Feature & Cracking & Yielding & Ultimate \\
\hline Value points & 2.2 & 8.7 & 18.9 \\
\hline Displacement $/ \mathrm{mm}$ & 11.7 & 20.3 & 25.9 \\
\hline Load/KN & & \\
\hline
\end{tabular}

Fig. 5 the comparison of load-displacement curve of KW-1

Before the $50 \%$ of the ultimate load, the wall is at the elastic stage, and the load and displacement are linear relationship. Before reaching the limit load, each feature point displacement values of crack, yield and failure stage are basically identical, and the change trend of displacement load curve is consistent, but load calculated value slightly larger than the test results as a whole. Finite element calculation of bearing capacity is $\mathrm{P}_{\mathrm{u}}{ }^{\prime}=27.7 \mathrm{kN}$, the ultimate bearing capacity is slightly greater than the test $\mathrm{P}_{\mathrm{u}}=25.9 \mathrm{KN}$, and the error is $6.9 \%$.

In the existing finite element model of multi-ribbed composite wall, block connected with rib, flat-fell seam is often ignored, and contact relationship is defined as the binding constraint, namely 
the interface coupled fully. But this definition with the actual circumstances of the specimen is not completely consistent. Block and the rib are usually two kinds of different cement base material, and both are successively pouring, the binding is not reliable. Therefore, in order to more accurately simulate the stress test model, this paper uses block and sash Tie firstly, commands operations defined as binding, and then deletes the binding relationship, and sets "ideal hard contact", namely the interface strain coordination, but only transfers pressure than traction. Because of the interface between the cohesive force and friction force affect convergence of the model, so when modeling it is ignored. Test data and the finite element data as shown in table 2.

Table 2 Test data and the finite element data of KW-2

\begin{tabular}{c|c|c}
\hline & Ultimate load $/ \mathrm{KN}$ & The limit displacement $/ \mathrm{mm}$ \\
\hline The test value & 96.2 & 13.0 \\
\hline Contact with calculated value & 87.0 & 20.3 \\
\hline Binding constraint computed value & 127.8 & 15.8 \\
\hline
\end{tabular}

Under the condition of the binding constraints, the limit displacement error is smaller. And under the condition of the contact, the error of the ultimate load is smaller. The reason is that contact ignores the adhesion and friction between the cash and the block, and the lateral displacement constraints of the wall is reduced, so the displacement value is larger; And, when defined as binding block, finite element models of the stress state is different from the experimental model of the block, therefore the bearing capacity of the wall error is bigger. As shown in figure 6 and figure 7 .
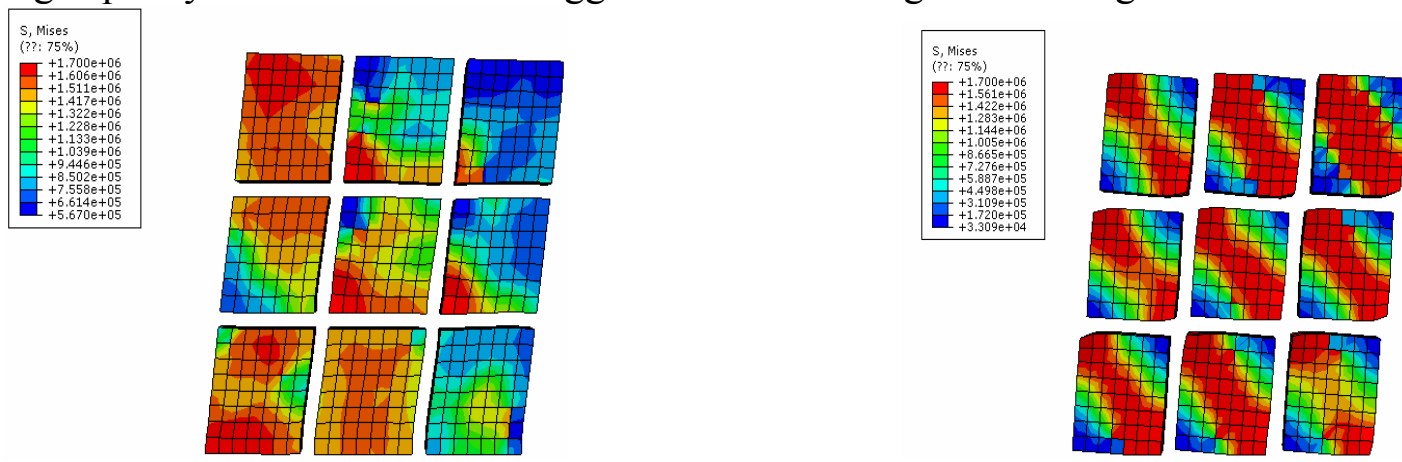

Fig.6 Mises stress nephogram of block with tie Fig.7 Mises stress nephogram of block with contact

In KW-2, when the test model under monotonic lateral force, the wall destroyed with most of the rib tie-beam form plastic hinge, and part of the rib beam steel has broken voice, and pressure side frame column angle shows signs of crushed concrete ${ }^{[7]}$. When ABAQUS model damages, the rib beam steel stress is more than the yield strength, and the destruction of the reinforcement is consistent with the original test, as shown in figure 8. Maximum principal plastic strain of frame column angle is larger, as shown in figure 9. Destroy of concrete frame and the destruction of the original test model shown in figure 10 are consistent.

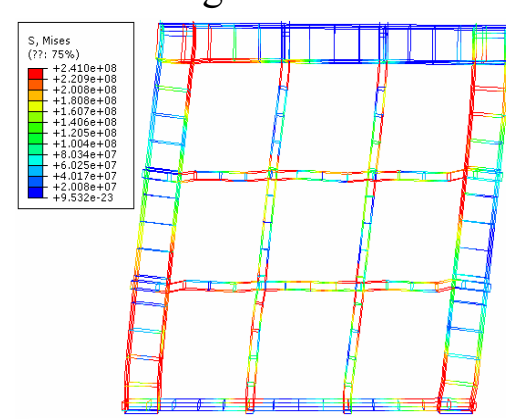

Fig.8 Mises stress nephogram of steel bar of KW-2

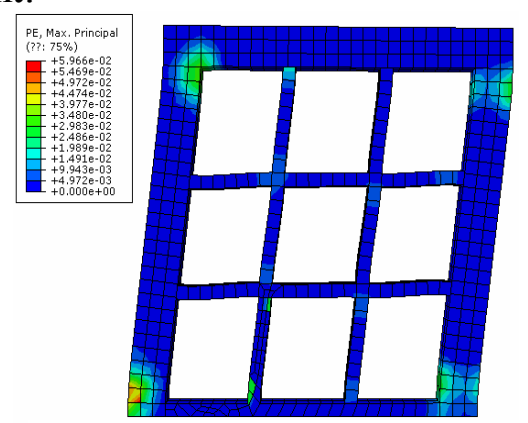

Fig.9 The max principal plastic strain nephogram of $\mathrm{KW}-2$

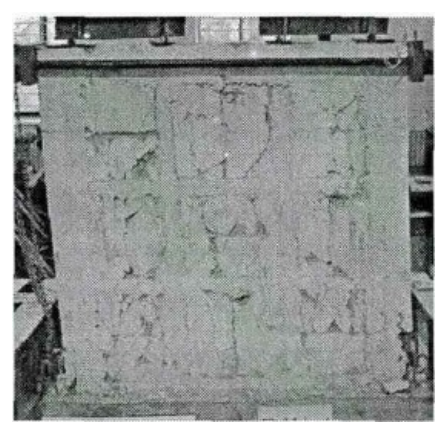

Fig.10 Final damage condition of $\mathrm{KW}-2$

Hysteresis curve is a curve of restoring force with the change of deformation. It reflects structure under repeated load stress performance, degradation and slip deformation characteristics, binding and energy consumption, and it summarizes the strength, stiffness and ductility, etc., and it is to determine the restoring force model and the basis of nonlinear seismic response analysis. 
Figure 11 and figure 12 are hysteretic curve and skeleton curve of KW-2 finite element model. We can see artifacts have obvious stages of elasticity, plasticity and damage. But the hysteresis curve shows spindle, and is fuller than the curve of the test mode ${ }^{[7]}$. This is because in the finite element model, assuming good cohesive force between reinforcement and concrete, reinforcing steel bar is embedded the concrete, no slippage between the two, so there is no pinched phenomenon of test model.
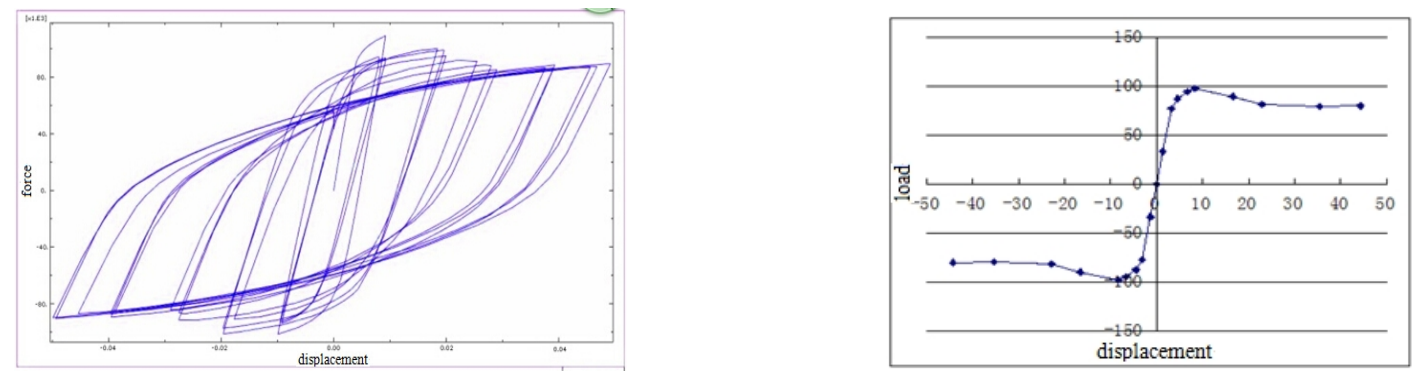

Fig. 11 hysteretic loop of the finite element model Fig. 12 skeleton curve of the finite element model

\section{Conclusions}

1. Multi-ribbed composite wall of ABAQUS finite element model was established, and we simulated test model KW-1 and KW-2 in literature [7]. The finite element model bearing capacity $\mathrm{P}_{\mathrm{u}}{ }^{\prime}=27.7 \mathrm{kN}$ of $\mathrm{KW}-1$ was slightly more than the ultimate bearing capacity $\mathrm{Pu}=25.9 \mathrm{kN}$ of the test, and the error is $6.9 \%$.

2. The limit displacement of KW-2 was $\Delta_{\mathrm{u}}=13.0 \mathrm{~mm}$, and the limit load was $\mathrm{P}_{\mathrm{u}}=96.2 \mathrm{kN}$. Between the block and the sash with binding conditions, the finite element limit displacement was $\Delta_{\mathrm{u}}{ }^{\prime}=15.8 \mathrm{~mm}$, and the error was $21.5 \%$; Calculate ultimate load was $\mathrm{P}_{\mathrm{u}}{ }^{\prime}=127.8 \mathrm{kN}$, and the error was $32.8 \%$. Between the block and the sash with the "ideal hard contact" conditions, finite element limit displacement was $\Delta_{\mathrm{u}}{ }^{\prime}=20.3 \mathrm{~mm}$, and the error was $56.2 \%$; Calculate ultimate load was $\mathrm{P}_{\mathrm{u}}{ }^{\prime}=87.0 \mathrm{kN}$, and the error was $10.6 \%$.Therefore, the block and the sash defined as binding, the limit displacement error was smaller, and the block and the sash defined as hard contact, the limit load error was smaller. 3. Through the analysis of the finite element model and the test data of filled block wall, the hysteresis curve of the test model showed the s-shaped, and finite element model of hysteresis curve showed fusiform, curve more full, which compared with the test model had a better energy dissipation capacity, but it still had a certain error with the test model. This was because the finite element model failed to simulate the relative slip between steel and concrete.

\section{References}

[1] Jianjing Jiang, Xinzheng Lu, Lieping Lu. Concrete structure finite element analysis [M].Beijing: Tsinghua University Press, 2005: 148-149.

[2] Jinchang Wang, Yekai Chen. The application of ABAQUS in civil engineering [M]. Zhejiang University Press, 2006: 84-85.

[3] Zhaoxia Li. Damage mechanics and its application [M].Beijing: Science Press, 2002.

[4] Yuzhuo Wang, Chuanguo Fu. Structural engineering analysis and example explanation of ABAQUS M]. Beijing: China Architecture and Building Press, 2010:34-54.

[5] $\mathrm{Hu} \mathrm{Lu}$. Research on Seismic Performance of the outer frame-multi-grid composite shear wall structures [D].Changsha: Hunan University, 2012.

[6] Weijun Yang, Chuxian Shi. Shear load-bearing capacity research of reinforced block masonry shear wall [J]. Journal of building structures. 2001, 39 (9):25-27.

[7] Meng Guo. Research on seismic performance and design calculation method of the frame-composite wall structure system [D].Beijing: Beijing Jiaotong University, 2011. 